\title{
PODER LOCAL, POLÍTICAS SOCIAIS E SUSTENTABILIDADE
}

\author{
Pedro Jacobi*
}

RESUMO: A problemática da sustentabilidade assume, neste final de século, um papel central na reflexão em torno das dimensões do desenvolvimento e das alternativas que se configuram para garantir eqüidade e articular as relações entre o global e o local. A área social é atualmente onde se explicitam os maiores desafios de respostas que possibilitem uma articulação dos diferentes interesses em jogo. A organização democrática do poder local assume cada vez mais um espaço central numa agenda que contemple a necessária articulação não só entre atores, mas entre politicas.

Nessa direção torna-se fundamental criar as condições para inserir crescentemente a problemática ambiental no universo da gestão local, e principalmente em relação à dinâmica das políticas sociais. O quadro socioambiental que caracteriza as sociedades contemporâneas revela que as ações dos humanos sobre o meio ambiente está causando impactos cada vez mais complexos, tanto em termos quantitativos quanto qualitativos. O conceito de desenvolvimento sustentável surge como uma idéia força integradora para qualificar a necessidade de pensar uma outra forma de desenvolvimento.

Nesse contexto, a participação se torna um meio fundamental de institucionalizar relações mais diretas, flexiveis e transparentes que reconheçam os direitos dos cidadãos; assim como de reforçar laços de solidariedade num contexto de pressão social e polarização política na direção de uma cidadania ativa que disponha dos instrumentos para o questionamento permanente da ordem estabelecida .

Experiências de Poder Local bem-sucedidas, principalmente por parte de administrações municipais, mostram que, havendo vontade politica, é possivel viabilizar ações governamentais pautadas pela adoção dos princípios de sustentabilidade ambiental conjugada a resultados na esfera do desenvolvimento econômico e social. O município possibilita, neste sentido, a articulação de políticas de caráter intersetorial do desenvolvimento social na medida em que se amplia o campo de análise e de atuação que inclui conceitos como qualidade de vida, exercício de direitos e expansão do desenvolvimento de capacidades.

PALAVRAS CHAVE: Poder local, cidadania, participação, meio ambiente, desenvolvimento sustentável

* Sociólogo. Professor da Faculdade de Fducação da (ISP e Presidente do Programa de Pós-Ciraduação em Ciência Ambiental da USP. Av. da Universidade, 308 sala 210 CEP 05508-900 - São Paulo - SP Fone/Fax: (11) 825-4409. email: pjacohi(a)cysnetwal.com.br 


\section{CONTEXTUALIZAÇÃO}

Na América Latina, a luta pela conquista de espaços para aumentar a participação social é, sem dúvida, um dos aspectos mais desafiadores para a análise sobre os alcances da democracia no que se refere às relações entre o nível local de governo e a cidadania.

Na década dos 90, a participação nas suas diversas dimensões vem sendo amparada e institucionalizada, na América Latina, dentro dos marcos das democracias representativas. A participação popular se transforma no referencial de ampliação de possibilidades de acesso dos setores populares dentro de uma perspectiva de desenvolvimento da sociedade civil e de fortalecimento dos mecanismos democráticos, mas também para garantir a execução eficiente de programas de compensação social no contexto das políticas de ajuste estrutural e de liberalização da economia e de privatização do patrimônio do Estado. Entretanto, o que se observa é que, em geral, as propostas participativas ainda permanecem mais no plano da retórica do que no da prática.

Observa-se que existe um déficit de participação e de constituição de atores relevantes, o que pode redundar em crescente fator de crise de governabilidade e de legitimidade. A insatisfação pela deterioração ou a falta de melhoria nos niveis de qualidade de vida, sem canais efetivos onde estes possam ser explicitados, pode conduzir à erosão da titularidade dos atores relevantes expressa em fenômenos como a volatilidade eleitoral e o desvirtuamento de propostas de gestão pautadas no aprofundamento das práticas democráticas. Poucas são as experiências de gestão municipal que assumem, de fato, uma radicalidade democrática na gestão da coisa pública, assim como ampliam concretamente 0 potencial participativo. A análise dos processos existentes está permeada pelos condicionantes da cultura política, tanto do Brasil como demais países da América Latina, marcados por tradições estatistas, centralizadoras, patrimonialistas e, portanto, por padrões de relação clientelistas, meritocráticos e de interesses criados entre Sociedade e Estado.

Entretanto, estes condicionantes não têm sido necessariamente um fator impeditivo para a emergência de uma diversidade de formas de participação dos setores populares, onde embora freqüentemente muitas se situem no escopo das práticas no contexto das tradições anteriormente descritas, outras as contradizem abertamente. 
O tema dos direitos e da cidadania assume dimensão relevante no contexto deste referencial analítico, na medida em que permite aprofundar o significado do impacto e das transformações ocorridas na relação Sociedade Civil/ Estado, desde meados da década de 80 .

A redefinição das relações entre Estado e sociedade civil no Brasil, no final dos anos 70 , implica na constituição, com muitos percalços, de uma esfera societária autônoma. O surgimento da sociedade civil brasileira está indissoluvelmente vinculado não apenas à emergência de movimentos sociais, mas ao processo pelo qual atores sociais modernos e democráticos surgiram, adquiriram uma nova identidade democrática e passaram a pressionar o Estado e o sistema político a se adaptarem a uma nova concepção acerca da moderna institucionalidade democrática.

Os atores sociais que emergem na sociedade civil após 1970, à revelia do Estado, criaram novos espaços e formas de participação e relacionamento com o poder público. Estes espaços foram construídos, tanto pelos movimentos populares como pelas diversas instituições da sociedade civil que articularam demandas e alianças de resistência popular e de lutas pela conquista de direitos civis e sociais. Muitos movimentos imprimiram sua marca e orientaram sua ação pela defesa de práticas pautadas pela sua autonomia, pela necessidade de tornar visivel a sua capacidade de auto-organizar-se e de desenvolver a democracia direta, transformando as carências do seu entorno de moradia em práticas reivindicatórias.

Os anos 80 trazem uma complexidade crescente das interações dos movimentos com os órgãos públicos e uma importância maior das assessorias especializadas e das articulações interinstitucionais. A crescente politização da esfera privada possibilita a construção de novos padrões de valores, configurando freqüentemente uma vinculação ideológica e política entre a necessidade e seus condicionantes estruturais. $O$ processo de envolvimento dos moradores, e a cada vez mais freqüente resposta do poder público em face das demandas, somada à participação dos profissionais e articuladores sociais ou assessores, possibilita a acumulação de conhecimento em torno das questões reivindicadas, vinculando-as às pautas institucionalizadas da sociedade e criando condições para a formulação de demandas junto aos órgãos públicos (JACOBI, 1990).

Deve-se destacar, também, o significado que as transformações do processo político mais amplo provocam na feição do movimento, na medida em que estes passam 
a ser reconhecidos cada vez mais como interlocutores válidos. Muitos movimentos apontam, a partir da reposição do coletivo, para uma qualidade diferenciada de participação na gestão da coisa pública, onde a representação não resume todo o esforço de organização, mas configura uma parte de um processo onde a população cria as condições para influenciar a dinâmica de funcionamento de um órgão do Estado.

Entretanto, a sua crescente importância no processo político se reflete, após 1988, nas vitórias de partidos progressistas em cidades brasileiras. Os movimentos não só exercem pressão sobre a arena política, mas ampliam seu espaço de inserção e conseguem também influenciar, às vezes, a agenda de gestões progressistas. Isto se verifica pela expansão do seu potencial participativo em conselhos de gestão tripartite, comissões de planejamento, orçamento participativo e outras formas específicas de representação.

Com os anos 90, além das práticas participativas inovadoras que se institucionalizam cada vez mais, surgem novos movimentos baseados em ações solidárias alternativas, centradas em questões éticas ou de revalorização da vida humana.

A década dos 80 , no plano político, consolidou a configuração de um marco institucional básico de democratização. Isto implica na necessidade de aperfeiçoamento dos instrumentos tendentes à concretização dos direitos sociais definidos na Constituição, enquanto definição de uma nova cidadania.

No processo de democratização no nivel social se destacam três perspectivas: as questões ligadas à eqüidade e às desigualdades sociais; a luta social pela definição dos conteúdos da democracia; e o processo de formação dos agentes sociais e dos atores coletivos no processo de emergência e consolidação da cidadania.

O processo de construção da cidadania é perpassado por paradoxos na medida em que se explicitam três dinâmicas concomitantes - o reconhecimento e a construção das identidades dos distintos sujeitos sociais envolvidos, o contexto da inclusão das necessidades expressas pelos distintos sujeitos sociais e a definição de novas agendas de gestão, notadamente no que se refere à extensão dos bens a amplos setores da população. Esta noção de cidadania está estruturada a partir de uma definição legal dos direitos e deveres que a constituem. 


\section{AS COMPLEXIDADES DA EXTENSÃO DA CIDADANIA NO BRASIL}

No Brasil, a reflexão sobre a cidadania se centra em torno dos obstáculos à sua extensão, decorrentes da cultura política tradicional, e nas perspectivas da sua transformação.

A nova dimensão da cidadania inclui, de um lado, a constituição de cidadãos enquanto sujeitos sociais ativos, e de outro, para a sociedade como um todo, um aprendizado de convivência com esses cidadãos emergentes que recusam permanecer nos lugares que thes foram definidos social e culturalmente.

O tema da participação se insere dentro da nova polarização dos ideais democráticos. Este modelo requer, para sua efetiva implantação, um conjunto de prérequisitos, como, a melhoria de condições materiais dos grupos sociais mais excluídos através da redistribuição de recursos materiais, a redução do poder burocrático, a garantia de sistemas de informação abertos e a institucionalização de princípios de autonomia democrática.

No Brasil, o modelo de gestão pública, até o final da década dos setenta, estava estruturado com base na concentração do poder decisório e da execução no nivel do governo federal, definindo atribuições e competências residuais para o nivel estadual e definindo para os municípios atribuições de interesse local. Este processo se transforma significativamente a partir da crise do modelo existente e das mudanças no desenho político-institucional.

A noção de participação popular está associada, desde os anos 60 , ao debate internacional sobre o desenvolvimento. Teve maior repercussão nos anos 70 , quando do fortalecimento das propostas alternativas de desenvolvimento e da desilusão com relação à própria capacidade do Estado de controlá-lo e planificá-lo. O fato do mesmo conceito e as práticas que propõe ser utilizado por diferentes ideologias, desperta dúvidas e desconfianças quanto aos resultados possiveis. Os diferentes atores do cenário de desenvolvimento conceberam a participação de diversas formas e promoveram e/ ou se opuseram a distintas iniciativas participativas com perspectivas temporais e expectativas diferenciadas. 
O discurso predominante prestou pouca atenção aos desafios lançados pelas práticas de democracia de base, de cooperação e comunitárias, que buscam reverter a lógica de dependência dos setores populares. Durante os anos 80 a participação perdeu espaço no discurso internacional à imagem e semelhança das visões de desenvolvimento orientadas pela defesa de principios de justiça social e bem-estar humano. No início dos anos 90, o tema volta adquirir atualidade, trazendo à tona as ambiguidades tanto entre tutela e autonomia, como a que decorre das exigências da economia de mercado em contraposição com as aspirações de justiça social.

\section{PARTICIPAÇÃO: DINÂMICAS CONTRADITÓRIAS, TENSÕES E LIMITES}

No contexto da transição pós-democrática no Brasil e por força das pressões de uma sociedade civil mais ativa e mais organizada foram sendo criados novos espaços públicos de interação, mas principalmente de negociação. Nesse contexto, a participação citadina emerge principalmente como referencial de rupturas e tensões e as práticas participativas, associadas a uma mudança qualitativa da gestão, assumem visibilidade pública e repercutem na sociedade.

Um primeiro aspecto refere-se à inevitável associação que sempre é feita com a crise de representatividade e a emergência de movimentos sociais que reivindicam e questionam a sua desigual inserção no contexto urbano. Isto está diretamente relacionado, de um lado, com o declínio das instituições mediadoras, erodindo as fontes tradicionais de formação de consenso e enfraquecendo os meios através dos quais os cidadãos são formalmente representados. De outro lado, e de forma concomitante, ocorrem transformações no modus operandi da administração pública em virtude das necessidades impostas pelo processo de democratização. Estas se consubstanciam na multiplicação de iniciativas, desde meados dos anos 70 , de um lento processo de reorganização das estruturas administrativas a partir da introdução de alguns componentes democráticos na estrutura hierárquica e funcional.

As transformações na dinâmica de gestão e o fortalecimento de práticas que tornam legítima a participação citadina estão, direta ou indiretamente, associadas à necessidade de imprimir também maior eficiência à ação governamental. Trata-se de tema permeado por contradições em virtude das transformações em curso, inclusive nos paises capitalistas avançados, a partir da crise do Welfare State e do fortalecimento 
das políticas neo-liberais. A lógica de desqualificação do papel do Estado e a defesa do Estado mínimo constituem a referência recorrente na concepção privatista da ideologia neo-liberal visando a gradual erosão dos direitos sociais, a desregulação e a redução dos fundos públicos, utilizando de forma perversa uma argumentação que privilegia a transferência para a sociedade civil de responsabilidades anteriormente vinculadas à ação do Estado.

As transformações político-institucionais e a ampliação de canais de representatividade dos setores organizados para atuarem junto aos órgãos públicos enquanto conquista dos movimentos organizados da sociedade civil mostram a potencialidade de construção de sujeitos sociais identificados por objetivos comuns na transformação da gestão da coisa pública, associado à construção de uma nova institucionalidade. Quando se fala de "participação dos cidadãos" deve se enfatizar que se trata de uma forma de intervenção na vida pública com uma motivação social concreta que se exerce de forma direta, baseada num certo nivel de institucionalização das relações Estado/sociedade (JACOBI, 1990).

O contexto da emergência de politicas públicas pautadas pelo componente participativo, está relacionado com as mudanças na matriz sociopolitica através de um maior questionamento sobre o papel do Estado como principal agente indutor das politicas sociais ${ }^{1}$. A formulação mais recorrente está estruturada em torno do aprofundamento do processo democrático, e do seu impacto na ampliação da capacidade de influência sobre os diversos processos decisórios em todos os niveis da atividade social e das instituições sociais.

Nesse sentido, a participação social se caracteriza como um importante instrumento de fortalecimento da sociedade civil, notadamente dos setores mais excluidos, na medida em que a superação das carências acumuladas dependem basicamente da interação entre agentes públicos e privados, no marco de arranjos sócioinstitucionais estratégicos. A participação social se enquadra no processo de redefinição entre o público e o privado, dentro da perspectiva de redistribuir o poder em favor dos sujeitos sociais que geralmente não têm acesso. Trata-se de pensar o ordenamento das diferenças dentro do marco de questionamento sobre o papel do Estado enquanto regulador da sociedade.

1 A estrategia proposta pela CEPAL em documentos publicados nos anos 80 reconhecem a necessidade de adequar o Estado aos desafios de uma nova estratégia de inclusão nos processos sociopoliticos dos cidadãos na qualidade de cidadãos plenamente participativos. 
As normas de participação dos cidadãos devem definir obrigações públicas e mecanismos legais, criando, na medida do possivel, condições para a existência de uma engenharia institucional composta por um espectro diversificado de instâncias tais como: entidades de interesse municipal, conselhos consultivos da cidade e dos distritos, iniciativas dos cidadãos e consultas populares por distrito.

A participação deve ser entendida como um processo continuado de democratizaçẳo da vida municipal, cujos objetivos são: 1) promover iniciativas a partir de programas e campanhas especiais visando o desenvolvimento de objetivos de interesse coletivo; 2) reforçar o tecido associativo e ampliar a capacidade técnica e administrativa das associações e 3 ) desenvolver a participação na definição de programas e projetos e na gestão dos serviços municipais (JACOBI,1990).

A concepção conciliar passa a ter uma presença crescente no Brasil a partir da legitimação do papel inovador dos diversos tipos de conselhos enquanto facilitadores da presença da sociedade civil na gestão pública.

A participação se torna um meio fundamental de institucionalizar relações mais diretas e flexiveis e transparentes que reconheçam os direitos dos cidadãos; assim como de reforçar laços de solidariedade num contexto de pressão social e polarização política na direção de uma cidadania ativa que disponha dos instrumentos para o questionamento permanente da ordem estabelecida.

Para tanto é necessário que da sociedade civil surjam interlocutores coletivos grupos comunitários, movimentos sociais, e na medida do possivel, atores sociais desarticulados, mas motivados para o engajamento em práticas participativas - que tornem possivel uma participação ativa e representativa, sem que o Estado exija quaisquer tipos de dependência administrativa e financeira. Isto cria, portanto, as condições de romper com as práticas tradicionais - populismo, autoritarismo, clientelismo, assistencialismo, mandonismo, patrimonialismo e privatização da política nas suas diversas acepções. A participação na gestão da coisa pública, enquanto corretivo das limitações da democracia representativa, possibilitam, pelo menos em tese, o engajamento da sociedade civil na formulação de políticas públicas e no controle das ações governamentais e dos negócios públicos.

A importância do desenvolvimento da participação direta reside principalmente na potencial incorporação de grupos sociais e de valores socioculturais diferentes dos 
que prevalecem nos organismos públicos. Entretanto, não se deve desconsiderar as contradições que podem surgir no processo, seja quanto à formação de um duplo poder, seja quanto ao controle de instâncias decisórias pelos grupos mais ativos e consolidados, em detrimento dos setores mais excluídos, que encontram nos mecanismos de participação direta uma primeira forma de reconhecimento dos seus interesses (JACOBI,1990).

O arranjo institucional participativo ampliado se consolida na medida em que se viabiliza a capacidade dos grupos de interesse de influenciar, direta ou indiretamente a formulação e gestão de políticas públicas. A ampliação da oferta citadina no processo assume um caráter diferenciador não só quanto à legitimidade, mas principalmente quanto à garantia de governabilidade e de democratização da gestão dos bens públicos.

A consolidação de propostas participativas representa a potencialização e a ampliação de práticas comunitárias através do estabelecimento e ativação de um conjunto de mecanismos institucionais que reconheçam direitos efetivamente exerciveis e estimulem estratégias de envolvimento e co-responsabilização. Nesse sentido, um dos maiores desafios de uma proposta participativa ampliada é o de garantir a definição de critérios de representação, de forma a impedir, tanto a sua manipulação por grupos guiados por interesses particularizados, como a possibilidade da sua instrumentalização pela administração pública.

\section{PODER LOCAL E O DESAFIO DA SUSTENTABILIDADE}

A problemática da sustentabilidade assume, neste final de século, um papel central na reflexão em torno das dimensões do desenvolvimento e das alternativas que se configuram para garantir eqüidade e articular as relações entre o global e o local. A área social é atualmente onde se explicitam os maiores desafios de respostas que possibilitem uma articulação dos diferentes interesses em jogo. A organização democrática do poder local assume cada vez mais um espaço central numa agenda que contemple a necessária articulação não só entre atores, mas entre políticas.

Nessa direção, torna-se fundamental criar as condições para inserir crescentemente a problemática ambiental no universo da gestão local, e principalmente em relação à dinâmica das políticas sociais. $O$ quadro socioambiental que caracteriza as sociedades contemporâneas revela que as ações dos humanos sobre o meio ambiente 
está causando impactos cada vez mais complexos, tanto em termos quantitativos quanto qualitativos. $O$ conceito de desenvolvimento sustentável surge como uma idéia força integradora para qualificar a necessidade de pensar uma outra forma de desenvolvimento. Seu fundamento provém da necessidade percebida de busca de um equilibrio em relação às capacidades e às limitações existentes. $O$ desenvolvimento e o bem estar humanos requerem um equilíbrio dinâmico entre população, capacidade do meio ambiente $\mathrm{e}$ vitalidade produtiva.

Dentre as transformações mundiais nestas duas décadas, aquelas vinculadas à degradação ambiental e à crescente desigualdade entre regiões assumem um lugar de destaque que reforçou a importância de adotar esquemas integradores. Embora ambos os processos tenham sidos concebidos inicialmente de maneira fragmentada, sem vinculações evidentes, hoje se torna mais explícita a sua articulação dentro da compreensão no plano de uma crise que assume dimensões globais. Articulam-se, portanto, de um lado, os impactos da crise econômica dos anos 80 e a necessidade de repensar os paradigmas existentes; e de outro, o alarme dado pelos fenômenos decorrentes da destruição do meio ambiente.

Assim, o que se observa é que enquanto se agravavam os problemas sociais e se aprofundava a distância entre os países pobres e os industrializados, emergiram, com mais impacto, diversas manifestações da crise ambiental, que se relacionam diretamente com os padrões produtivos e de consumo prevalecentes. Este contexto gerou condições de maior repercussão para um questionamento do processo em curso que busca articular desenvolvimento e meio ambiente.

A partir de 1987, com a divulgação do Relatório Brundtlandt² ${ }^{2}$ também conhecido como "Nosso Futuro Comum", a idéia do "desenvolvimento sustentável" é retomada; representando um ponto de inflexão no debate sobre os impactos do desenvolvimento. O relatório é o resultado de um trabalho de uma comissão da ONU, e parte de uma abordagem em torno da complexidade das causas que originam os problemas socioeconômicos e ecológicos da sociedade global. Não só reforça as necessárias relações entre economia, tecnologia, sociedade e política, como chama a atenção para a necessidade do reforço de uma nova postura ética em relação à preservação do meio

2 Este relatório é o resultado do trabalho da comissão da ONU World Comission on Environment and Development presidida por Gro Harlem Brundtlandt e Mansour Khalid, dai o nome do relatório final. 
ambiente, caracterizada pelo desafio de uma responsabilidade tanto entre as gerações quanto entre os integrantes da sociedade dos nossos tempos.

O Relatório Brundtlandt apresenta uma lista de ações a serem desenvolvidas pelos Estados e também define metas a serem realizadas no nivel internacional, tendo como agentes as diversas instituições multilaterais. Os resultados neste final de década estão muito aquém das expectativas e decorrem da complexidade de estabelecer e pactuar limites de emissões, proteção da biodiversidade, notadamente pelos paises mais desenvolvidos.

No processo que conduziu à Conferência das Nações Unidas sobre o Meio Ambiente e o Desenvolvimento - a Rio 92 - o enfoque foi adotado como um marco conceitual que presidiu todo o processo de debates, declarações e documentos formulados. Assim a interdependência entre o desenvolvimento socioeconômico e as transformações no meio ambiente, durante décadas ignorada, entrou tanto no discurso como na agenda de grande parte dos governos do mundo. A Conferência representou um primeiro passo de um longo processo de entendimento entre as nações sobre as medidas concretas visando "reconciliar as atividades econômicas com a necessidade de proteger o planeta e assegurar um futuro sustentável para todos os povos". O relatório representa o que, segundo alguns analistas, pode ser denominado de reformismo otimismo, desde a perspectiva de expansão do sistema econômico dominante.

O conceito de desenvolvimento sustentável representa um importante avanço, na medida em que considera a complexa relação entre o desenvolvimento e o meio ambiente numa variedade de áreas.

A adoção do conceito por organismos internacionais marca a afirmação de uma filosofia do desenvolvimento que a partir de um tripé combina eficiência econômica com justiça social e prudência ecológica, como premissas da construção de uma sociedade solidária e justa.

As dimensões apontadas pelo conceito de desenvolvimento sustentável contemplam o cálculo econômico, o aspecto biofísico e o componente sociopolítico, enquanto referenciais para a interpretação do mundo e para possibilitar interferências na lógica predatória prevalecente. 
O desenvolvimento sustentável não se refere especificamente a um problema limitado de adequações ecológicas de um processo social, mas a uma estratégia ou modelo múltiplo para a sociedade, que deve levar em conta tanto uma viabilidade econômica quanto ecológica. Num sentido abrangente, a noção de desenvolvimento sustentável à necessária redefinição das relações sociedade humana - natureza e portanto, a uma mudança substancial do próprio processo civilizatório.

Freqüentemente, observa-se o conceito de desenvolvimento sustentável como idéia força integradora, apesar do consenso que tem sido construído, e que serve para impulsionar os enfoques integradores entre meio ambiente e desenvolvimento, assim como de forma paralela entre economia e ecologia.

Pode se afirmar que ainda prevalece a transcendência do enfoque sobre o desenvolvimento sustentável e que este radique mais na sua capacidade de idéia força, nas suas repercussões intelectuais e no seu papel articulador de discursos e de práticas atomizadas, em que apesar de seguir fragmentados têm uma matriz única originada na existência de uma crise ambiental, econômica e também social.

O desenvolvimento sustentável somente pode ser entendido como um processo onde, de um lado, as restrições mais relevantes estão relacionadas com a exploração dos recursos, a orientação do desenvolvimento tecnológico e o marco institucional. De outro, o crescimento deve enfatizar os aspectos qualitativos, notadamente aqueles relacionados com a eqüidade, o uso de recursos - em particular da energia -, e a geração de resíduos e contaminantes. Além disso, a ênfase no desenvolvimento deve fixar-se na superação dos déficits sociais, nas necessidades básicas e na alteração de padrões de consumo, principalmente nos países desenvolvidos, para poder manter e aumentar os recursos base, sobretudo os agrícolas, energéticos, bióticos, minerais, ar e água.

Assim, a idéia de sustentabilidade implica na prevalência da premissa de que é preciso estabelecer uma limitação definida nas possibilidades de crescimento e um conjunto de iniciativas que levem em conta a existência de interlocutores e participantes sociais relevantes e ativos através de práticas educativas e de um processo de diálogo informado, o que reforça um sentimento de co-responsabilização e de constituição de valores éticos. Isto também implica em que uma política de desenvolvimento na direção de uma sociedade sustentável não pode ignorar nem as dimensões culturais, nem as relações de poder existentes e, muito menos, o reconhecimento das limitações ecológicas, sob pena de apenas manter um padrão predatório de desenvolvimento. 
Atualmente o avanço rumo a uma sociedade sustentável é permeado de obstáculos, na medida em que existe uma restrita consciência na sociedade a respeito das implicações do modelo de desenvolvimento em curso. Pode-se afirmar que as causas básicas que provocam atividades ecológicamente predatórias podem ser atribuídas às instituições sociais, aos sistemas de informação e comunicação e aos valores adotados pela sociedade. Isto implica principalmente na necessidade de estimular uma participação mais ativa da sociedade no debate dos seus destinos, como uma forma de estabelecer um conjunto socialmente identificado de problemas, objetivos e soluções. O caminho a ser desenhado passa necessariamente por uma mudança no acesso à informação e por transformações institucionais que garantam acessibilidade e transparência na gestão. Existe um desafio essencial a ser enfrentado, e este está centrado na possibilidade que os sistemas de informações e as instituições sociais se tornem facilitadores de um processo que reforce os argumentos para a construção de uma sociedade sustentável, a partir de premissas centradas no exercício de uma cidadania ativa e a mudança de valores individuais e coletivos. Para tanto, é preciso que se criem todas as condições para facilitar o processo, suprindo dados, desenvolvendo e disseminando indicadores e tornando transparentes os procedimentos através de práticas centradas na educação ambiental que possa garantir os meios de criar novos estilos de vida, desenvolver uma consciência ética que questione o atual modelo de desenvolvimento marcado pelo seu caráter predatório e pelo reforço das desigualdades socioambientais.

A sustentabilidade como novo critério básico e integrador precisa estimular permanentemente as responsabilidades éticas, na medida em que a ênfase nos aspectos extra-econômicos serve para reconsiderar os aspectos relacionados com a eqüidade, a justiça social e a ética dos seres vivos.

\section{A NECESSIDADE DE IMPLEMENTAR POLÍTICAS DE SUSTENTABILIDADE}

A reflexão em torno das políticas sociais em um contexto marcado pela degradação permanente do meio ambiente e do seu ecossistema não pode prescindir da análise dos determinantes do processo, dos atores envolvidos e das formas de organização social que potencializa novos desdobramentos e alternativas de ação numa perspectiva de sustentabilidade.

A noção de sustentabilidade implica uma necessária interpelação entre justiça social, qualidade de vida, equilíbrio ambiental e a necessidade de desenvolvimento com 
capacidade de suporte. Mas também se associa a uma premissa da garantia de sustentação econômico-financeira e institucional. No nosso entender, a ênfase é na direção de práticas pautadas por um desenvolvimento de políticas sociais que se articulam com a necessidade de recuperação, conservação, melhoria do meio ambiente e da qualidade de vida.

A configuração desse novo paradigma se concretiza de forma efetiva através da ampliação e democratização das relações de poder, através de práticas participativas de discussão das políticas públicas e do compartilhamento das informações e do estímulo ao debate público sobre o significado social das ações desenvolvidas. A possibilidade de comprometimento público dos diversos atores sociais envolvidos potencializa a articulação de políticas públicas dentro de uma perspectiva de consolidar uma abordagem estratégica de desenvolvimento social, participativa, intersetorial e sustentável do ponto de vista socioambiental.

Nesse sentido, o município pode assumir um papel estratégico promovendo o debate em torno das principais linhas de ação, dentro das premissas da construção de uma Agenda 21 Local. A Agenda 21, principal documento emanado da Rio 92, abre a possibilidade de uma nova perspectiva pactuada no enfrentamento dos problemas socioambientais em busca de um novo modelo de desenvolvimento, com mais justiça social e preservação do meio ambiente. A Agenda 21 Local deve ser construída a partir de processos participativos onde a população e/ou as comunidades possam compreender a sua responsabilidade individual e coletiva no processo de desenvolvimento.

Cabe ao Poder Local a tarefa de fomentar políticas que estimulem a participação dos indivíduos dentro de uma perspectiva intersetorial reforçando diálogos que estimulem uma compreensão dos processos a partir dos seus componentes, sociais, econômicos, ecológicos, espaciais e culturais.

No contexto urbano metropolitano brasileiro os problemas ambientais têm se avolumado a passos agigantados e a sua lenta resolução tem se tornado de conhecimento público pela virulência do seu impacto - aumento desmesurado de enchentes, dificuldades na gestão dos resíduos sólidos e interferência crescente do despejo inadequado de resíduos sólidos em áreas potencialmente degradáveis em termos ambientais, impactos cada vez maiores da poluição do ar na saúde da população. 
A preocupação com o desenvolvimento sustentável representa a possibilidade de garantir, mudanças sociopoliticas que não comprometam os sistemas ecológicos e sociais nos quais se sustentam as comunidades. É cada vez mais notória a complexidade desse processo de transformação de um cenário urbano crescentemente não só ameaçado, mas diretamente afetado por riscos e agravos socioambientais.

Adotamos os argumentos de BECK (1994) relativos à configuração de uma lógica da distribuição de riscos. Isto é plenamente compativel com os aspectos acima apresentados, uma vez que o desafio que está colocado é o de criar as condições para, se não reduzir, pelo menos atenuar o preocupante quadro de riscos existentes, que afeta desigualmente a população. Os riscos, segundo BECK, estão diretamente relacionados com a modernidade reflexiva e os, ainda imprevisíveis, efeitos da globalização.

O tema da sustentabilidade se confronta com o que Beck denomina de "paradigma da sociedade de risco". Isto implica a necessidade da multiplicação de práticas sociais pautadas pela ampliação do direito à informação e de educação ambiental numa perspectiva integradora. Trata-se de potencializar iniciativas a partir do suposto que maior acesso à informação e transparência na gestão dos problemas ambientais urbanos pode implicar uma reorganização de poder e autoridade.

A passagem da compreensão dos problemas ambientais de uma ótica mais centrada nas ciências naturais para um escopo mais abrangente sobre o tema inclui, também, o componente social, ampliando a compreensão da questão para uma dimensão socioambiental, não se esquecendo de levar em conta critérios culturais e determinações específicas das políticas sociais.

A preocupação com o tema do desenvolvimento sustentável introduz não apenas a sempre polêmica questão da capacidade de suporte, mas também os alcances e limites das ações destinadas a reduzir o impacto dos agravos no cotidiano urbano e as respostas pautadas por rupturas no modus operandi da omissão e conivência com as práticas autofágicas predominantes.

Torna-se preciso incrementar os meios e o acesso à informação, assim como o papel indutivo do poder público na oferta de conteúdos informacionais e educativos, emergem indagações quanto aos condicionantes de processos que ampliem as possibilidades de alteração do atual quadro de degradação socioambiental. 
O tema dos residuos sólidos é provavelmente aquele que melhor exemplifica as possibilidades de formulação de políticas públicas minimizadoras ou preventivas. Entretanto, a timidez das iniciativas e a descontinuidade das políticas têm criado um verdadeiro círculo vicioso pautado pela lógica da paralisia, e o enfrentamento através de práticas alternativas da lógica do status quo. Diversas experiências bem sucedidas de gestão a partir de práticas alternativas mostram que é possivel romper com o círculo vicioso existente e engajar a população em ações pautadas pela co-responsabilização e compromisso com a defesa do meio ambiente a partir de interdependências com os setores de saúde e educação.

O principal desafio que se coloca nos dias atuais é que as cidades, independente do seu porte, criem as condições para assegurar uma qualidade de vida que possa ser considerada aceitável, não interferindo negativamente no meio ambiente do seu entorno e agindo preventivamente para evitar a continuidade do nivel de degradação, notadamente nas regiões habitadas pelos setores mais carentes.

A sua inclusão dentro da esfera da sustentabilidade ambiental implica uma transformação paradigmática, constituindo-se num elemento complementar para atingir um desenvolvimento econômico compativel com a busca de eqüidade.

A modernização dos instrumentos requer uma engenharia socioinstitucional complexa apoiada em processos pedagógicos para garantir condições de acesso dos diversos atores sociais envolvidos, e notadamente dos grupos sociais mais vulneráveis às informações em torno dos serviços públicos e dos problemas ambientais.

Tendo como referência o agravamento dos problemas e a crescente sensação de paralisia e insolubilidade dos impactos destrutivos da crise do metabolismo urbano, o desafio ambiental urbano deve se centrar em ações que dinamizem o acesso à consciência ambiental dos cidadãos a partir de um intenso trabalho de educação.

Mas também é importante estar consciente das dificuldades que hoje existem para viabilizar, por exemplo, propostas que articulam redução da degradação ambiental com geração de renda. Embora este tema seja objeto de projetos pautados pela vontade politica dos administradores municipais, nem sempre a intencionalidade é bem sucedida ou bem compreendida pelos moradores. Trata-se de programas que exigem um período de amadurecimento e cuja legitimação é bastante lenta, por parte dos diversos estratos sociais. 
O cenário atual, marcado pela crescente exclusão social provocada por um mercado de trabalho cada vez mais seletivo, introduz um fator complicador, uma vez que um número cada vez maior de pessoas não têm outra opção senão trabalhar em empregos socialmente excluídos. O grande desafio que se coloca é, por um lado, gerar empregos com práticas sustentáveis e, por outro, fazer crescer o nivel de consciência ambiental, ampliando as possibilidades de a população participar mais intensamente nos processos decisórios como um meio de fortalecer a sua co-responsabilização na fiscalização e controle dos agentes responsáveis pela degradação socioambiental.

Finalmente, é importante ressaltar que uma agenda para a sustentabilidade ambiental urbana deve levar em conta a relevância de estimular a expansão dos meios de acesso a uma informação geralmente dispersa e de difícil compreensão como parte de uma política de fortalecimento do papel dos diversos atores intervenientes.

O momento atual exige que a sociedade esteja mais motivada e mobilizada para assumir um caráter mais propositivo, assim como para poder questionar de forma concreta a falta de iniciativa dos governos para implementar politicas pautadas pelo binômio sustentabilidade e desenvolvimento num contexto de crescentes dificuldades para promover a inclusão social.

Diversas experiências bem sucedidas, principalmente por parte de administrações municipais, mostram que, havendo vontade politica, é possível viabilizar ações governamentais pautadas pela adoção dos princípios de sustentabilidade ambiental conjugada a resultados na esfera do desenvolvimento econômico e social. Estas também mostram que é no municipio que é mais fácil desenvolver a ação combinada de vários programas que tenham o mesmo foco. O municipio possibilita, neste sentido, a articulação de politicas de caráter intersetorial do desenvolvimento social na medida em que se amplia o campo de análise e de atuação que inclui conceitos como qualidade de vida, exercício de direitos e expansão do desenvolvimento de capacidades.

\section{REFERÊNCIAS BIBLIOGRÁFICAS}

BECK, U. Risk society. London, Sage Publications.1994.

JACOBI, P. Descentralização municipal e a participação dos cidadãos: apontamentos para o debate. Revista Lua Nova (20), 1990. 
JACOBI, P., coord. Pesquisa sobre problemas ambientais e qualidade de vida na cidade de São Paulo. São Paulo, SEl/Cedec,1994.

JACOBI, P. Ampliação da cidadania e participação: desafios da democratização da relação poder público/sociedade civil no Brasil. São Paulo, 1996. [Tese de Livre Docência - Faculdade de Educação da Universidade de São Paulo].

SUMMARY: The problem of sustainability represents at the end of this century a central role as to the analysis on the dimensions of development and the existing alternatives to enable equity and articulation between local and global issues. The social sector is where these challenges become more visible, thus representing a very stimulating arena to articulate different interests at stake. The democratic organization of local power increasingly assumes more space within an agenda that includes the necessary articulation not only between actors, but also between policies.

Thus it is fundamental to create the conditions to include increasingly the environmental issues within the universe of local administration, and mainly as to the dynamics of social policies. The socio-environmental framework that characterizes contemporary societies indicates that the impact of humans on environment is causing more and more complex impacts, both quantitative as qualitative. The concept of sustainable development arises as an integrating idea to qualify the need to think development from another perspective of the established order.

Within this context, participation becomes a necessary way to institutionalize more direct, flexible and transparent relations that help to recognize the rights of citizens, strengthen ties of solidarity in a context of social pressure and political polarization towards an active citizenship with a permanent questioning of the established order. Local power good practices, mainly by municipal administrations, indicate that granted political will, it is possible to make feasible governmental actions characterized by the adoption of the principles of environmental sustainability associated to outcomes in the sphere of social and economic development $A$ municipality can be seen as a very stimulating locus to experiment an articulation of intersectorial policies of social development as it enlarges the field of action including concepts such as quality of life, practice of rights and expansion of the development of social capital.

KEY WORDS: Local power, citizenship, participation, environment, sustainable development 